\title{
Upaya Peningkatan Penjualan Pada Pelaku Usaha Rumahan Kelurahan Cigadung, Kecamatan Karang Tanjung, Pandeglang, Banten Melalui E- COMMERCE
}

\author{
${ }^{1}$ Erly Krisnanik, ${ }^{2}$ Tri Rahayu, ${ }^{3}$ Anita Muliawati \\ 1,2,3 Fakultas Ilmu Komputer, Universitas Pembangunan Nasional "Veteran” Jakarta \\ email: ${ }^{1}$ erly74@gmail.com; ${ }^{2} a y u \_s m l @ y a h o o . c o m ;{ }^{3}$ muliawati_2002@yahoo.com.
}

\begin{abstract}
The Law of the Republic of Indonesia Number 20 Year 2008 About Usaha Mikro Kecil Menengah (UMKM) One point in clause 4 says that empowerment for UMKM is very necessary in order to increase self-reliance, togetherness and entrepreneurship, and one item in clause 5 says that grow and develop the ability of UMKM into a strong and independent business. Based on the above, the objectives and targets of the program of community service activities performed by servants in the sub-district of Cigadung subdistrict Karang Tanjung Pandeglang Banten are: 1) to increase the growth rate of sales of home business actors by utilizing ICT as a medium of marketing products on-line; 2) to improve the quality of life, independence, and economic welfare hence required assistance and big involvement of the local government tools, as well as various parties including institutions of higher education as a form of dedication to the community is needed concrete support. The methods to be used in this PPM program are lecture / exposure methods and practices to provide insight into marketing strategies by utilizing ICTs, and creating e-commerce websites. The resulting output is a product of e-commerce website that can be utilized by home-based business actors to be able to update products offered at any time with reference to marketing strategy.
\end{abstract}

Keywords: UMKM, e-commerce, on-line sales

\begin{abstract}
Abstrak. Undang-Undang Republik Indonesia Nomor 20 Tahun 2008 Tentang Usaha Mikro, Kecil, Dan Menengah salah satu butir pada pasal 4 mengatakan bahwa pemberdayaan bagi UMKM sangat diperlukan dalam rangka meningkatkan kemandirian, kebersamaan dan kewirausahaan, serta salah satu butir pada pasal 5 mengatakan bahwa menumbuhkan dan mengembangkan kemampuan Usaha Mikro, Kecil, dan Menengah menjadi usaha yang tangguh dan mandiri. Berdasarkan hal tersebut maka tujuan dan target dari program kegiatan pengabdian kepada masyarakat yang dilakukan pengabdi diwilayah kelurahan Cigadung kecamatan Karang Tanjung Pandeglang Banten adalah: 1) untuk meningkatkan laju pertumbuhan penjualan pelaku usaha rumahan dengan memanfaatkan TIK sebagai media memasarkan produk secara on-line; 2) untuk meningkatkan kualitas hidup, kemandirian, dan kesejahteraan ekonomi maka diperlukan pendampingan dan keterlibatan yang besar dari perangkat pemerintah daerah, serta berbagai pihak termasuk institusi perguruan tinggi sebagai wujud pengabdian kepada masyarakat sangat dibutuhkan dukungannya secara kongkrit. Metode yang digunakan dalam program kegiatan PPM ini adalah metode ceramah/paparan dan praktek untuk memberikan masukkan tentang strategi pemasaran dengan memanfaatkan TIK, dan membuat website e-commerce. Luaran yang dihasilkan adalah sebuah produk berupa website e-commerce yang bisa dimanfaatkan oleh pelaku usaha rumahan untuk dapat mengupdate produk-produk yang ditawarkan setiap saat dengan mengacu pada strategi pemasaran.
\end{abstract}

Kata Kunci: UMKM, e-commerce, penjualan on-line, 


\section{4 | Erly Krisnanik, et al.}

\section{Pendahuluan}

Undang-Undang Republik Indonesia Nomor 20 Tahun 2008 Tentang Usaha Mikro, Kecil, Dan Menengah pada pasal 4 mengatakan bahwa prinsip pemberdayaan Usaha Mikro, Kecil, dan Menengah adalah : a) Penumbuhan kemandirian, kebersamaan, dan kewirausahaan Usaha Mikro, Kecil, dan Menengah untuk berkarya dengan prakarsa sendiri; b) Perwujudan kebijakan publik yang transparan, akuntabel, dan berkeadilan; c) Pengembangan usaha berbasis potensi daerah dan berorientasi pasar sesuai dengan kompetensi Usaha Mikro, Kecil, dan Menengah; d) Peningkatan daya saing Usaha Mikro, Kecil, dan Menengah; e) Penyelenggaraan perencanaan, pelaksanaan, dan pengendalian secara terpadu. Sedangkan tujuan dari pemberdayaan UMKM menurut pasal 5 adalah: a) Mewujudkan struktur perekonomian nasional yang seimbang, berkembang, dan berkeadilan; b) Menumbuhkan dan mengembangkan kemampuan Usaha Mikro, Kecil, dan Menengah menjadi usaha yang tangguh dan mandiri; c) Dan meningkatkan peran Usaha Mikro, Kecil, dan Menengah dalam pembangunan daerah, penciptaan lapangan kerja, pemerataan pendapatan, pertumbuhan ekonomi, dan pengentasan rakyat dari kemiskinan.

Perkembangan TIK telah menjadi salah satu media bagi UKM untuk memasarkan produk yang telah mereka hasilkan guna meningkatkan daya saing perusahaan. Mengingat di era globalisasi ini arena persaingan menjadi sangat kompetitif, dan bersifat global/ mendunia, usaha kecil dan menengah (UKM) harus mampu bersaing di tengah persaingan, untuk itu diperlukan strategi guna meningkatkan daya saing perusahaan.

TIK telah menjadi solusi bagi banyak permasalahan di dunia usaha terutama untuk pemanfaatan teknologi internet. Dengan adanya penjualan on-line dapat meringankan beban kinerja dari UKM terutama di bagian pemasaran dan dapat mempercepat proses transaksi jual beli, meringankan biaya transaksi serta meningkatkan komunikasi antara penjual dan pembeli tanpa dibatasi ruang dan waktu. Permasalahannya tidak semua pengusaha UMKM mengenal dan memahami TIK sebagai media untuk memasarkan produk sekaligus menjual produk secara on-line karena beberapa alasan seperti terbatasnya pengetahuan dan kemampuan untuk mengunakan komputer mengakibatkan mereka tidak berani mengambil resiko berinvestasi menggunakan TIK, terbatasnya biaya/ modal menyebabkan kemampuan untuk membeli terbatas, kurangnya SDM yang bisa dijadikan sebagai admin sistem untuk mengelola aplikasi

Dengan melihat pentingnya upaya pemberdayaan pelaku bisnis untuk meningkatkan kualitas hidup, kemandirian, dan kesejahteraan ekonomi maka diperlukan pendampingan dan keterlibatan yang besar dari perangkat pemerintah daerah, serta berbagai pihak termasuk institusi perguruan tinggi sebagai wujud pengabdian kepada masyarakat sangat dibutuhkan dukungannya secara kongkrit. Program kegiatan tersebut dilakukan melalui pelatihan dan pendampingan penggunaan TIK sebagai penunjang pemasaran produk yang dihasilkan dalam dunia usaha.

Tidak semua Pelaku Usaha yang berada di Kelurahan Cigadung terdaftar sebagai UKM, dengan modal sendiri mereka mendirikan bisnis di rumah dengan keterbatasan modal untuk dipasarkan ke pasar lokal. Kelurahan Cigadung merupakan salah satu dari kelurahan Duren Mekar berada dibawah kecamatan Karang Tanjung dikota Pandengalang Banten. Khalayak sasaran dalam kegiatan pengabdian pada masyarakat ini adalah pelaku usaha yang ada disana sebanyak kurang lebih 15 orang diberikan pembinaan untuk memanfaatkan TIK dalam memasarkan produknya. Mereka yang diberikan pelatihan adalah mereka yang belum memiliki on-line shop.

\section{Metode Pengabdian}

Metode yang dilakukan untuk pelaksanaan pengabdian kepada masyarakat adalah melakukan sosialisasi dan pembekalan mengenai pemasaran produk dan pembuatan website ecommerce secara bertahap. Adapun tahapan kegiatan tersebut adalah sebagai berikut:

1. Memberikan pembekalan kepada peserta UMKM dengan cara ceramah/paparan materi untuk memberikan masukkan tentang strategi pemasaran dengan memanfaatkan TIK sebagai media untuk menjual produk secara on-line 
2. Melakukan praktek langsung membuat website e-commerce dengan menggunakan:

a. Situs www.123website.co.id atau www.tokopedia.co.id yang sifatnya tidak berbayar.

b. Dan penggunaan sosial media (facebook, tweeter, dan IG) sebagai ajang untuk iklan penjualan.

3. Melakukan evaluasi kegiatan dengan memberikan postest capaian pembelajaran selama pelatihan.

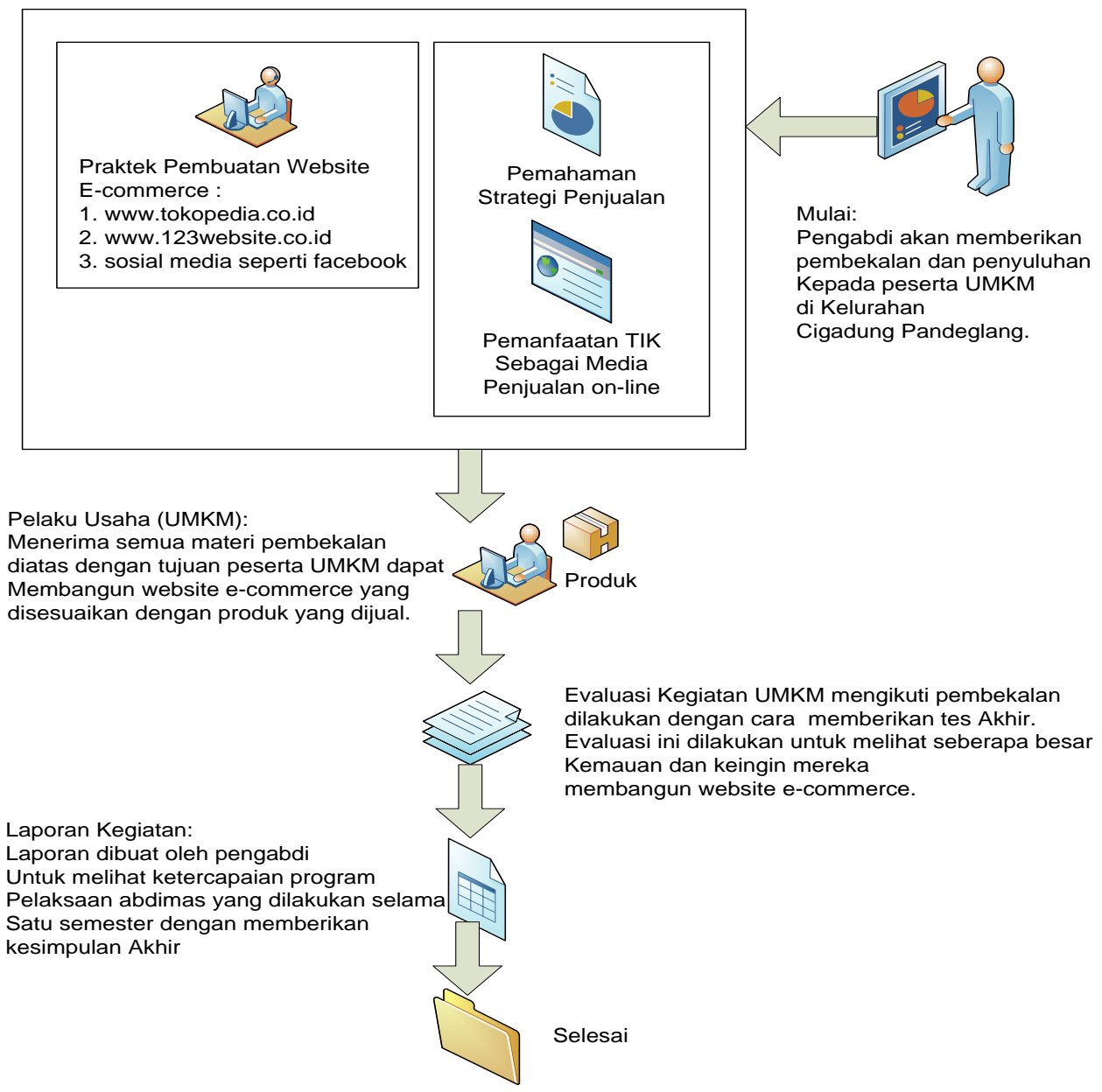

Gambar 1. Metodologi Pengabdian Kepada Masyarakat

\section{Hasil dan Pembahasan}

Pelaksanaan pengabdian kepada masyarakat bertujuan untuk memberikan pengetahuan dan pemahaman tentang memasarkan produk yang telah di buat oleh UMKM di kelurahan Cigadung Karang Tanjung Pandeglang, Karena dengan pemasaran yang baik maka hasil produksi dapat meningkat begitu pula dengan pendapatan para UMKM. Strategi untuk meningkatkan penjualan produk UMKM yaitu melalui penggunaan TIK dan pemahaman teknik pemasaran secara on-line. Pelaku usaha kelurahan Cigadung Pandeglang membangun sebuah aplikasi e-commerce dengan fasilitas situs free seperti www.wordpress.com , www.tokopedia.co.id dan www.123website.co.id . Selain website mereka juga memanfaatkan sosial media seperti www.facebook.com, www.tweeter.com dan IG yang mengarahkan calon pelanggan untuk membuka website e-commerce sehingga dapat menarik calon pembeli lebih banyak lagi. 
Rancangan aplikasi e-commerce berisi tentang informasi produk, mekanisme pemesanan, mekanisme pembayaran dan mekanis pengiriman barang. Berikut adalah gambar rencana strategi pelaku UMKM untuk memanfaatkan teknologi Informasi dan Komunikasi (TIK) sebagai media penjualan on-line.

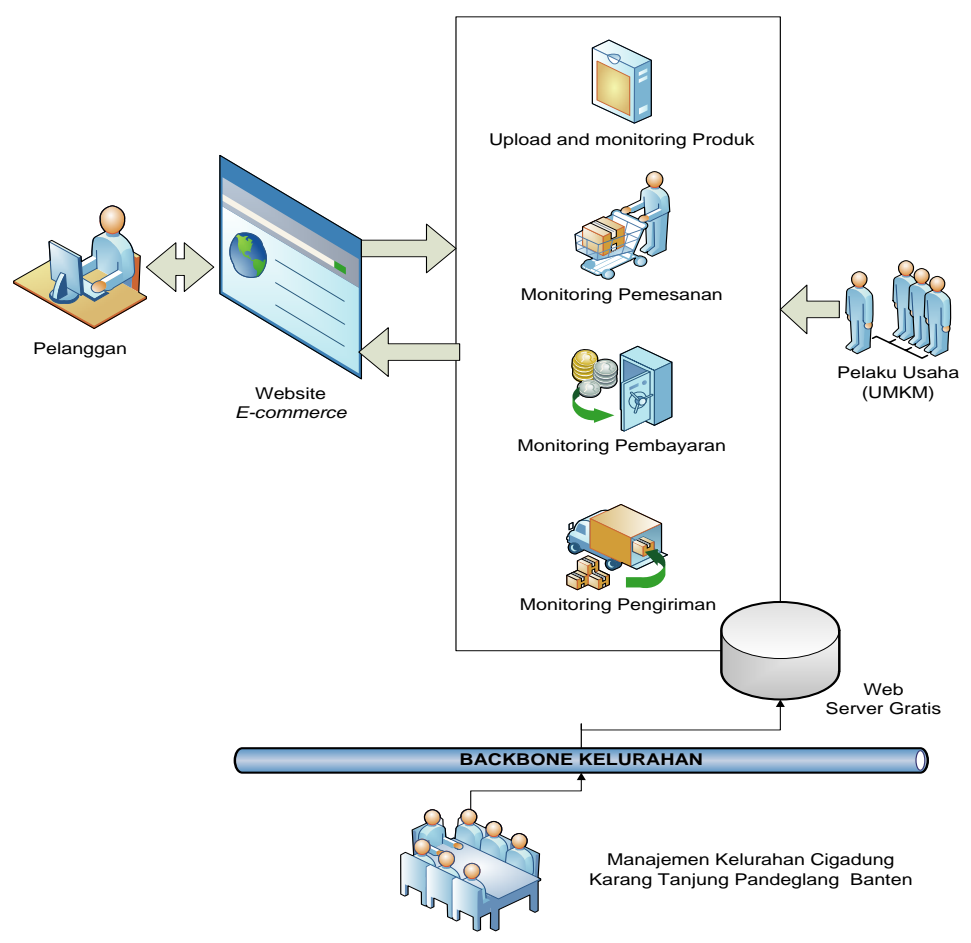

Gambar 2. Strategi meningkatkan penjualan dengan pemanfaatan TIK melalui e-commerce

Hasil pembekalan yang telah dilaksanakan oleh pengabdi kepada peserta UMKM dilakukan pengukuran untuk mengetahui tingkat pemahaman, menguasai dan mengimplementasikan ilmu yang telah didapat selama pendampingan terkait dengan konsep dan teknik penjualan secara on-line melalui e-commerce. Berikut adalah tabel kegiatan dengan indikator ketercapaian. Tabel tersebut menunjukkan indikator capaian dari setiap tahapan kegiatan yang dilakukan oleh pengabdi agar dapat diukur sejauh mana transfer pengetahuan dapat diserap oleh pelaku usaha (UMKM).

Tabel 1. Tahapan kegiatan pelaksanaan meliputi tahap sebagai berikut:

\begin{tabular}{|c|l|l|}
\hline $\begin{array}{c}\text { Tahap } \\
\text { Ke }\end{array}$ & \multicolumn{1}{|c|}{ Kegiatan } & \multicolumn{1}{c|}{ Indikator } \\
\hline 1. & $\begin{array}{l}\text { Memberikan sosialisasi } \\
\text { tentang teknik pemasaran. }\end{array}$ & $\begin{array}{l}\text { Dilakukan Pretest dan Postest untuk menilai } \\
\text { pencapaian peningkatan pemahaman materi } \\
>75 \% .\end{array}$ \\
\hline 2. & $\begin{array}{l}\text { Memberikan } \\
\text { pendampingan dan } \\
\text { penyuluhan serta tanya } \\
\text { jawab. }\end{array}$ & $\begin{array}{l}\text { Dapat meningkatkan pengetahuan dan } \\
\text { pemahaman dalam Penjualan on-line meliputi: } \\
\text { 1) Penggunaan Jejaring Sosial Media sebagai } \\
\text { media untuk memasarkan produk secara on- } \\
\text { line } \\
\end{array}$ \\
& $\begin{array}{l}\text { 2) Penggunaan lapak secara on-line dengan } \\
\text { memanfaatkan salah satu web portal seperti } \\
\text { Toko Pedia. } \\
\text { 3) Pembuatan Web UMKM di kelurahan }\end{array}$ \\
\hline
\end{tabular}




\begin{tabular}{|c|l|l|}
\hline & & \multicolumn{1}{|c|}{$\begin{array}{l}\text { Cigadung melalui UMKM Sri Rahayu } \\
\text { sebagai pilot projek. }\end{array}$} \\
\hline 3 & $\begin{array}{l}\text { Memberikan } \\
\text { pendampingan untuk } \\
\text { pengelolaan toko on-line. }\end{array}$ & $\begin{array}{l}\text { Dapat mengoperasionalkan komputer dan } \\
\text { menjalankan aplikasi untuk memasarkan produk } \\
\text { secara on-line. }\end{array}$ \\
\hline
\end{tabular}

Pada tahapan kegiatan sosialisasi tentang teknik pemasaran pengukuran dilakukan dengan adanya pretest dan postest dengan standar capaian $>75 \%$. Hasil dari kegiatan tersebut dapat dilihat pada tabel di bawah ini:

\begin{tabular}{|c|c|c|c|}
\hline \multirow[t]{2}{*}{ No } & \multirow[t]{2}{*}{ Pertanyaan } & \multicolumn{2}{|c|}{ NILAI } \\
\hline & & PRETEST & POSTEST \\
\hline 1 & $\begin{array}{l}\text { Teknik pemasaran yang baik untuk } \\
\text { meningkatkan penjualan barang dan jasa }\end{array}$ & 71,5 & 85,8 \\
\hline 2 & $\begin{array}{l}\text { Apakah dengan e-commerce dapat lebih } \\
\text { mudah menjual barang dan jasa }\end{array}$ & 50 & 86,6 \\
\hline 3 & $\begin{array}{l}\text { Kepedulian dan keinginan untuk menjalankan } \\
\text { usaha menggunakan sistem internet }\end{array}$ & 71,5 & 85,8 \\
\hline 4 & $\begin{array}{l}\text { Kepedululian terhadap pesaing yang } \\
\text { menjalankan usahanya secara elektronik atau } \\
\text { terkomputerisasi }\end{array}$ & 42,9 & 71,5 \\
\hline 5 & $\begin{array}{l}\text { Kepedulian terhadap pesaing yang } \\
\text { menjalankan usahanya menggunakan sistem } \\
\text { internet }\end{array}$ & 57,2 & 71,5 \\
\hline 6 & $\begin{array}{l}\text { Pengetahuan tentang model menjalankan } \\
\text { usaha secara elektonik yang cocok }\end{array}$ & 57,2 & 85,8 \\
\hline 7 & $\begin{array}{l}\text { Memahami peluang dan ancaman dalam } \\
\text { menjalankan usaha secara elektronik atau } \\
\text { terkomputerisasi }\end{array}$ & 20 & 70 \\
\hline 8 & $\begin{array}{l}\text { Bagaimana e-commerce dapat meningkatkan } \\
\text { penjualan }\end{array}$ & 57,2 & 85,8 \\
\hline 9 & $\begin{array}{l}\text { Memahami dampak positif dan negatif } \\
\text { menjalankan usaha secara elektronik atau } \\
\text { terkomputerisasi dalam melakukan usaha di } \\
\text { lingkungan industry }\end{array}$ & 50,8 & 80 \\
\hline 10 & $\begin{array}{l}\text { Memahami dampak positif dan negatif } \\
\text { menjalankan usaha menggunakan sistem } \\
\text { internet dalam melakukan usaha di lingkungan } \\
\text { industri }\end{array}$ & 50 & 86 \\
\hline 11 & $\begin{array}{l}\text { Memahami tentang kegagalan dalam } \\
\text { menjalankan usaha menggunakan sistem } \\
\text { internet bagi organisasi apakah akan menjadi } \\
\text { gagal/kalah dalam persaingan }\end{array}$ & 50,5 & 87 \\
\hline 12 & $\begin{array}{l}\text { Apakah perlu ada kerjasama dengan PEMDA } \\
\text { untuk penerapan e-commerce terkait kesiapan } \\
\text { sarana dan prasarana yang memadai. }\end{array}$ & 80 & 90 \\
\hline & TOTAL SCORE & 658,8 & 985,8 \\
\hline
\end{tabular}

Dari tabel tersebut dapat disimpulkan bahwa telah ada peningkatan hasil pemahaman dan pengetahuan dari para pelaku usaha yang semula rata-rata nilai capaiannya adalah $54.9 \%$ kemudian setelah diberikan pembekalan menjadi $82.15 \%$. Berdasarkan Indikator capaian pada kegiatan pertama sudah melampaui $>75 \%$. 
Pada kegiatan kedua pengabdi telah memberikan pelatihan untuk membuat website sederhana dengan menggunakan situs gratis seperti www.123website.co.id dan www.worldpress.com serta pemanfaatan sosial media menggunakan facebook dan IG. Hampir semua peserta telah memiliki sosial media dari 15 peserta ada 11 yang memiliki. Namun dari ke 15 peserta belum memiliki website e-commerce. Dengan adanya pelatihan ini pengabdi memberikan pelatihan untuk membangun website UMKM, dari 15 peserta yang mengikuti pelatihan baru 10 yang sudah jadi.

Pada kegiatan ketiga pengabdi melakukan pendampingan kepada pelaku usaha rumahan (UMKM) terhadap website yang telah dibuat. Dari 10 website yang ada yang masih berjalan dengan baik dan dipelihara oleh pelaku uasaha tersebut hanya ada 7. Hal ini dikarenakan keterbatasan sarana dan prasarana karena mereka harus bermodal dengan ketersediaan jaringan internet.

Berdasarkan hasil pengabdian kepada masayarakat terhadap pelaku usaha rumahan (UMKM) di kelurahan Cigadung kelurahan Karang tanjung kabupaten Pandeglang Banten, agar kegiatan ini menjadi kegiatan yang berkelanjutan maka perlu adanya peningkatan kerjasama melalui program resource sharing antara Kelurahan dengan pihak kampus. Sehingga target yang ingin dicapai untuk meningkatkan penjualan dan daya saing para pelaku usaha rumahan (UMKM) dapat tercapai sesuai dengan program pemerintah.

\section{Kesimpulan}

Kegiatan Pengabdian Kepada Masyarakat telah dilaksanakan di kelurahan Cigadung Karang Tanjung Pandeglang Banten. Kegiatan pengabdian kepada masyarakat yang dilakukan melibatkan 15 orang peserta UMKM dan ibu rumah tangga. Untuk melihat ketercapaian hasil kegiatan pengabdi telah melakukan pretest dan postest dengan hasil pretest dan postest secara rata-rata mengalami kenaikan dari rata-rata nilai 54,90 (lima puluh empat koma sembilan puluh) menjadi rata-rata 82,15 (Delapan puluh dua koma lima belas) yang artinya, UMKM mendapatkan manfaat secara teori dan praktek dalam pemanfaatan TIK untuk mamasarkan produk secara on-line, dari kondisi belum banyak mengetahui tentang teknik pemasaran yang baik menjadi lebih memahami dan dapat mengetahui manfaat penggunaan TIK melalui aplikasi social media dan web portal yang dapat membantu pelaksanaan dalam memberikan pelayanan yag terbaik bagi masyarakat kelurahan Cigadung. Adapun salah satu produk hasil pelatihan pembuatan web sederhana menggunakan www.tokopedia.co.id dan www.123website.co.id. Saat ini upaya untuk memasarkan produk mereka masih menggunakan jasa layanan website yang free (tidak berbayar). Hal ini dilakukan untuk menumbuhkan rasa percaya UMKM dalam memanfaatkan TIK dan memudahkan mereka bersosialisasi menggunakan sarana dan prasarana yang biasa mereka gunakan seperti facebook, tweeter dan instagram. Kegiatan ini berkelanjutan dengan bermitra pada pihak kelurahan agar UMKM yang ada di fasilitasi sarana dan prasarana untuk koneksi ke jaringan internet secara terpadu.

\section{Daftar pustaka}

Bertha Silvia Sutejo, 2006, Internet marketing: Konsep dan Persoalan Baru Dunia Pemasaran” Jurnal Manajemen, Vol.6, No.1, Nov 2006 “)

Fandi Tjiptono, Gregorius Chandra dan Dedi Adriana, 2008, Pemasaran Strategik, Penerbit Andy, Jakarta.

Fandi Tjiptono, Gregorius Chandra, 2011, Service, Quality dan Satisfaction, Penerbit Andy, Jakarta.

Kotler, Philip and Amstrong, Gary, 2012, Principles Of Marketing, Fourteen Edition, Pearson Education Limited, England

Kotler, Keller, 2009, Manajemen Pemasaran, Edisi ke ketiga belas, Penerbit Airlangga, Jakarta.

Kotler, Philip dan AB Susanto, 2000, Manajemen Pemasaran di Indonesia Analisis, Perencanaan, Implementasi dan Pengendalian. Penerbit Salemba Empat, Jakarta. 
Kalakota and Whinston. (1996). Frontiers Of Electronic Commerce, Addison-Wesley Publilshing Company, Inc, Massachusetts.

M. Suyanto. (2005) Artikel: Aplikasi IT untuk UKM Menghadapi Persaingan Global. Kedaulatan Rakyat. Yogyakarta

Muslichah Erma Widiana1, Henky Supit2, Sri Hartini2, 2012, Penggunaan Teknologi Internet dalam Sistem Penjualan Online untuk Meningkatkan Kepuasan dan Pembelian Berulang Produk Batik pada Usaha Kecil dan Menengah di Jawa Timur,Jurnal Manajemen dan Kewirausahaan, Vol.14,No.1, Maret 2012:72-82

Oviliani Yenty Yuliana, Penggunaan Teknologi Internet dalam Bisnis, 2000, Jurnal Akuntansi \& Keuangan Vol. 2, No. 1, Mei 2000: 36 - 52.

Sumber Online:

http://banten.antaranews.com/berita/22124/bupati-laju-pertumbuhan-ekonomi-Pandeglangpositif diakses 27 April 2015.

Undang-Undang Republik Indonesia Nomor 20 Tahun 2008 Tentang Usaha Mikro, Kecil. 